\title{
Los encargos a sociedades mixtas en la actual Ley de Contratos del Sector Público
}

\section{Orders to mixed companies in the current Public Sector Contract Law}

\author{
Juan Alemany Garcías \\ Universitat Rovira i Virgili (España) \\ alemanypm10@icaib.org
}

\begin{abstract}
NOTA BIOGRÁFICA
Juan Alemany Garcías se doctoró en Derecho por la Universitat Rovira i Virgili, con la calificación de Sobresaliente Cum laude en el año 2015. Es profesor asociado de Derecho Administrativo en dicha universidad y de la Universidad de las Illes Balears. Sus principales líneas de investigación se centran en la contratación pública y el urbanismo, con seis monografías publicadas.
\end{abstract}

\section{RESUMEN}

En la tradicional legislación general básica sobre contratación pública, la sociedad de economía mixta era tratada como una modalidad de gestión indirecta de servicios públicos, tal y como se desprendía literalmente del art. 275 en relación con el 277 del Texto Refundido de la Ley de Contratos del Sector Público del año 2011, pero también en el ámbito local, concretamente en el art. 85.2.b de la Ley 7/1985 de Bases de Régimen Local. Las sociedades de economía mixta han tenido que adaptar su contratación al régimen propio de la contratación pública de la ley 9/2017 de 8 de noviembre. La transición del derecho privado al derecho público ha tenido ciertas dificultades en gran medida por las deficiencias legislativas que una norma redactada para las administraciones públicas provoca cuando se aplica a poderes adjudicadores que no son administración pública. La complejidad de la contratación de esta figura no se agota con la ley de contratos del sector público, sino que alcanza la aplicación de otras normas originalmente destinadas a las administraciones. La Ley $9 / 2017$ de 8 de noviembre destina un título a la contratación de las sociedades de economía mixta, pero presenta importantes controversias que generan inseguridad jurídica y que son desarrolladas a lo largo del presente artículo.

\section{PALABRAS CLAVE}

Mixta, socio privado, gestión indirecta, transparencia, licitación.

\begin{abstract}
In the traditional basic general legislation on public procurement, the mixed economy society was treated as a modality of indirect management of public services, as literally followed by art. 275 in relation to 277 of the Consolidated Text of the Public Sector Contract Law of 2011, but also at the local level, specifically in art. 85.2.b of Law 7/1985 on Bases of Local Regime. The mixed economy companies have had to adapt their contracting to the public procurement regime of Law 9/2017 of November 8 . The transition from private law to public law has had some difficulties to a large extent due to legislative deficiencies that a rule written for public administrations causes when applied to contracting authorities that are not public administration. The complexity of contracting this figure is not exhausted by the law of public sector contracts, but rather
\end{abstract}


REALA. Nueva Época - N. 12, octubre-marzo 2019 - ISSN: 1989-8975 - DOI: 10.24965/reala.i12.10704 - [Págs. 111-125]

Los encargos a sociedades mixtas en la actual Ley de Contratos del Sector Público

Juan Alemany Garcías

reaches the application of other rules originally intended for administrations. Law 9/2017 of November 8 allocates a title to the hiring of mixed economy societies, but it presents important controversies that generate legal uncertainty and are developed throughout this article.

\section{KEYWORDS}

Mixed, private partner, indirect management, transparency, tender.

\section{SUMARIO}

INTRODUCCIÓN. 1. NATURALEZA DE LAS DENOMINADAS SOCIEDADES DE ECONOMÍA MIXTA, ESPECIALMENTE EN LA LEY 9/2017 DE CONTRATOS DEL SECTOR PÚBLICO DE 8 DE NOVIEMBRE. 2. LA SOCIEDAD DE ECONOMÍA MIXTA EN LA LEGISLACIÓN DE RÉGIMEN LOCAL. 3. CONSTITUCIÓN DE LAS SOCIEDADES MIXTAS EN EL ÁMBITO LOCAL. 4. LA DISPOSICIÓN ADICIONAL VIGÉSIMO NOVENA DE LA LEY DE CONTRATOS DEL SECTOR PÚBLICO 9/2017 DE 8 DE NOVIEMBRE. ANÁLISIS JURISPRUDENCIAL. CONCLUSIONES. BIBLIOGRAFÍA.

\section{INTRODUCCIÓN}

Con arreglo al Libro Verde sobre la colaboración público-privada y el Derecho comunitario en materia de contratación pública y concesiones (COM/2004/0327 final) la creación de sociedades de economía mixta para la gestión de servicios públicos se considera una operación de colaboración público-privada (CPP) de tipo institucionalizado. Este tipo de operaciones de CPP implican la creación de una entidad en la que participan, de manera conjunta, un socio público y uno de privado ${ }^{1}$. La puesta en marcha de una CPP institucionalizada como reza el citado Libro Verde puede llevarse a cabo bien a través de la creación de una entidad en la que participan de manera conjunta el sector público y el sector privado, o bien mediante la participación en una empresa pública existente por parte del sector privado a través de la adquisición de una parte de su capital. En los Estados miembros, en este contexto, se utilizan para referirse a estas estructuras terminología y fórmulas diferentes (por ejemplo, el Kooperationsmodell, las CPP asociativas o las joint-ventures) (Gallego Córcoles, I., 2011: 2).

La Comisión Europea destaca que en los Estados miembros, las autoridades públicas recurren a veces a estas estructuras, en particular para la gestión de servicios públicos a escala local (por ejemplo, en el caso de los servicios de abastecimiento de agua o de recogida de residuos urbanos). La cooperación directa entre los socios público y privado en una entidad con personalidad jurídica a ojos de la CE permite que el socio público conserve un nivel de control relativamente elevado sobre el desarrollo de las operaciones, que a lo largo del tiempo puede ir adaptando en función de las circunstancias, a través de su presencia en el accionariado y en los órganos de decisión de la entidad común. Asimismo, permite al socio público desarrollar su experiencia propia en materia de explotación del servicio en cuestión, al tiempo que recurre a la ayuda de un socio privado. Este mecanismo de contratación para la gestión de un servicio público, donde se aúnan en un único procedimiento tanto la selección del socio privado que se integrara en la sociedad de economía mixta que gestionará el servicio como, en segundo lugar, la determinación de las condiciones de la gestión con definición de los derechos y obligaciones de las partes, ha sido también abordada por la "Comunicación interpretativa de la Comisión relativa a la aplicación del Derecho comunitario en materia de contratación pública y concesiones a la colaboración público-privada institucionalizada (CPPI)", que puede materializarse bajo dos modalidades ${ }^{2}$ :

- La creación de una nueva empresa cuyo capital pertenece conjuntamente a la entidad adjudicadora y al socio privado (en algunos casos, a varias entidades adjudicadoras y/o a varios socios privados), y la adjudicación de un contrato público o de una concesión a esa entidad de capital mixto, de nueva creación.

- Mediante la participación de un socio privado en una empresa pública existente que ejecuta contratos públicos o concesiones obtenidos anteriormente en el marco de una relación interna.

1 Libro Verde sobre la colaboración público-privada y el Derecho comunitario en materia de contratación pública y concesiones (COM/2004/0327), apartado 3.1.

2 DOUE de 12 de abril de 2008. 


\section{NATURALEZA DE LAS DENOMINADAS SOCIEDADES DE ECONOMÍA MIXTA, ESPECIALMENTE EN LA LEY 9/2017 DE CONTRATOS DEL SECTOR PÚBLICO DE 8 DE NOVIEMBRE}

En la Ley de contratos del sector público (Ley 9/2017, de 8 de noviembre, de Contratos del Sector Público, por la que se transponen al ordenamiento jurídico español las Directivas del Parlamento Europeo y del Consejo 2014/23/UE y 2014/24/UE, de 26 de febrero de 2014) recientemente aprobada por las Cortes Generales, desaparece la figura del contrato de gestión de servicio público y, con ello, la regulación de los diferentes modos de gestión indirecta de los servicios públicos en sede contractual que se contenía en el artículo 277 del anterior texto refundido. Aparece en su lugar, y en virtud de la Directiva 2014/23/UE del Parlamento Europeo y del Consejo, de 26 de febrero de 2014, relativa a la adjudicación de contratos de concesión, la «nueva» figura de la concesión de servicios de servicios, que se añade dentro de la categoría de las concesiones a la figura de la concesión de obras que ya contemplaba la antigua Ley de Contratos del sector público (Real Decreto Legislativo 3/2011, de 14 de noviembre, por el que se aprueba el texto refundido de la Ley de Contratos del Sector Público). Sin perjuicio de esta nueva regulación, el texto legal mantiene la posibilidad de que se adjudique directamente a una sociedad de economía mixta ${ }^{3}$ (Noguera de la Muela, B., 2012) un contrato de concesión de servicios o de obras en los términos recogidos en la Disposición adicional vigésima segunda, siguiendo la ya conocida jurisprudencia del Tribunal de Justicia de la Unión Europea (vid. Sentencia 196/08 en el caso ACOSET), y en la "Comunicación Interpretativa de la Comisión Europea relativa a la aplicación del derecho comunitario en materia de contratación pública y concesiones a la colaboración público-privada institucionalizada de 5 de febrero de 2008 (CPPI)".

La disposición adicional (DA) vigésima segunda de Ley 9/2017 bajo la rúbrica «Adjudicación de contratos de concesión de obras y de concesión de servicios a sociedades de economía mixta». dispone, en su apartado primero, que las concesiones de obras y de servicios podrán adjudicarse directamente a una sociedad de economía mixta en la que concurra mayoritariamente capital público con capital privado, siempre que la elección del socio privado se haya efectuado de conformidad con las normas establecidas en esta Ley para la adjudicación del contrato cuya ejecución constituya su objeto, y siempre que no se introduzcan modificaciones en el objeto y las condiciones del contrato que se tuvieron en cuenta en la selección del socio privado.

La disposición adicional 22.a en su apartado primero viene a contemplar la posibilidad de separar formalmente concesión de servicio y contrato de sociedad de la administración con otro u otros socios que van a asumir en particular la posición mayoritaria en la sociedad gestora del servicio, aportando lógicamente su experiencia y capacidad de organización empresarial en relación con el servicio y asumiendo la responsabilidad en su gestión. Lógicamente, a raíz de la disposición adicional 22 hemos de interpretar que si se obtiene otra concesión de servicio de parte de otra administración diferente que no forma parte de ella como socio, la forma de gestión será la de concesión y se regirá en cuanto a la gestión correspondiente por las mismas reglas que se regiría si fuese una empresa enteramente privada que hubiera obtenido tal concesión. Por ello, no existe ninguna novedad destacable excepto la estricta positivización de un principio o regla general establecida por la jurisprudencia del TJUE antes citada y que de hecho ya recogía la Disposición adicional vigésima novena del TRLCSP, que procedía a su vez de la Disposición adicional decimosexta, apartado treinta y cuatro de la Ley 2/2011, de 4 de marzo, de Economía Sostenible, que introdujo en la Ley de Contratos del Sector Público, una nueva Disposición adicional, la trigésima quinta, dedicada al régimen de adjudicación de los contratos públicos, en el marco de las formulas institucionales de colaboración entre el sector público y el sector privado.

Aunque la inexistencia de licitación en la adjudicación de la gestión de unos servicios resulta incompatible con los artículos 43 CE y 49 CE y con los principios de igualdad de trato y de no discriminación, es posible resolver este problema si se selecciona al socio privado respetando desde el momento en que se exija a los candidatos que demuestren, no sólo su capacidad para convertirse en accionistas, sino ante todo su capacidad técnica para prestar el servicio y las ventajas económicas y de otro tipo que conlleva su oferta (STJUE 196/08 en el caso ACOSET, apartado 59). En la medida en que los criterios de selección del socio

\footnotetext{
${ }^{3}$ Belén Noguera se ha referido a las dos opciones posibles para articular el encargo de gestión del servicio a la entidad mixta, entendiendo incluso que la «segunda opción, la licitación única, es por la que apuestan decididamente tanto el Parlamento Europeo como la Comisión y el propio Tribunal de Justicia de la Unión Europea, en su Sentencia de 15 de octubre de 2009 (As. C-196-08, Acoset SpA)».
} 
privado no se basen únicamente en el capital que aporta, sino también en su capacidad técnica y en las características de su oferta en cuanto a las prestaciones específicas que debe realizar, y en la medida en que se encomiende a dicho socio, como ocurre en el litigio principal, la explotación del servicio ${ }^{4}$ de que se trate y, por lo tanto, la gestión del mismo, cabe considerar que la selección del concesionario es un resultado indirecto de la selección del socio privado, decidida al término de un procedimiento respetuoso con los principios del Derecho comunitario (STJUE caso ACOSET, apartado 60).

La DA vigésima segunda de la nueva Ley de Contratos del Sector Público, añade también, en su apartado segundo, otra regla complementaria de la anterior que dispone, en la misma lógica de respeto a los principios de transparencia y de libre competencia recogidas en los artículos 43,49 y 86 del TCE, que en el caso en que la sociedad de economía mixta pretendiera acceder como concesionaria a otros contratos distintos de los referidos en el apartado 1 anterior, deberá concurrir al correspondiente procedimiento de licitación de conformidad con lo establecido en la presente Ley. Ello ha sido declarado por el TJUE en tanto que la aplicación de las normas establecidas en los artículos 12 CE, 43 CE y 49 CE, así como de los principios generales cuya expresión específica constituyen dichos artículos, estaría excluida en el supuesto de que, cumulativamente, la autoridad pública concedente ejerza sobre la entidad concesionaria un control análogo al que ejerce sobre sus propios servicios y dicha entidad realice la parte esencial de su actividad con la autoridad que la controla (véase en particular la sentencia ANAV, antes citada, apartado 24). En tal supuesto, la licitación no es obligatoria, aunque el contratante sea una entidad jurídicamente distinta de la entidad adjudicadora (véase en particular la sentencia de 10 de septiembre de 2009, Sea, C573/07, apartado 36). Pero contrariamente la participación, aunque sea minoritaria, de una empresa privada en el capital de una sociedad en la que participa asimismo la entidad adjudicadora de que se trate excluye, en cualquier caso, que dicha entidad adjudicadora pueda ejercer sobre la citada sociedad un control análogo al que ejerce sobre sus propios servicios (véase en particular la sentencia Sea, de 10 de septiembre de 2009, C573/07, antes citada, apartado 46).

Con arreglo a la jurisprudencia, la adjudicación de un contrato público a una empresa de economía mixta sin licitación previa sería contraria al objetivo de competencia libre y no falseada y al principio de igualdad de trato, ya que tal procedimiento otorgaría a la empresa privada que participa en el capital de la citada empresa una ventaja con respecto a sus competidores (sentencia Stadt Halle y RPL Lochau, apartado 51, y sentencia de 10 de noviembre de 2005, Comisión/Austria, C29/04, apartado 48) (Montoya Martín, E., 2009: 180 y 181). Abundando en los principios de transparencia y libre competencia, también en el último inciso del apartado primero de la DA vigésima segunda se dispone que la modificación de los contratos de concesión de obras o de concesión de servicios que se adjudiquen directamente según lo establecido en el párrafo anterior, únicamente se podrá realizar de conformidad con lo establecido en la Subsección $4 .^{a}$ de la Sección $3 .^{a}$ del Capítulo I del Título I del Libro Segundo, relativa a la modificación de los contratos. Nuevamente se trata de la positivización de la jurisprudencia del TJUE según la cual es necesario precisar que una sociedad de capital mixto, público y privado, debe conservar el mismo objeto social todo el tiempo que dure la concesión, y que toda modificación sustancial del contrato obligaría a proceder a una licitación (véase en este sentido la STJUE de 19 de junio de 2008, Caso Nachrichtenagentur, C454/06, apartado 34 y la citada sentencia caso ACOSET, apartado 62) ${ }^{5}$.

Por último el texto de la LCSP de 2017 se ocupa de un aspecto nada negligible cuál es la regulación de los medios de financiación vinculados a la concesión que la sociedad concesionaria puede tener en sus manos. Así el apartado tercero de la DA vigésimo segunda de nueva LCSP establece que: «sin perjuicio de la posibilidad de utilizar medios de financiación tales como emisión de obligaciones, empréstitos o créditos participativos, las sociedades de economía mixta constituidas para la ejecución de un contrato de concesión de obras o de concesión de servicios, podrán:

\footnotetext{
4 Por no encontrar suficientemente probada la concurrencia de las causas correspondientes, la STSJ Catalunya 126/2016, de 9 de marzo de 2016 (recurso 23/2013) ha anulado el Acuerdo adoptado el 6 de noviembre de 2012 por el Consell Metropolità de l'Área Metropolitana de Barcelona (CMB), que aprobó el establecimiento y prestación del servicio del ciclo integral del agua, el establecimiento del sistema de gestión de ese servicio público mediante sociedad de capital social mixto bajo la modalidad de convenio con sociedad existente (Sociedad General de Aguas de Barcelona, S. A.: SGAB), los estatutos de la nueva sociedad de capital mixto «Aigües de Barcelona, Empresa Metropolitana de Gestió del Cicle Integral de l'Aigua, Societat Anònima», y el convenio suscrito por Área Metropolitana de Barcelona y la Sociedad General d'Aigües de Barcelona, S. A. (SGAB). En un sólidamente fundamentado voto particular el Presidente de la Sala, el Magistrado Alberto Andrés Pereira, mostró su parecer de que en el caso se cumplían las circunstancias para la adjudicación directa, dada la trascendental concesión de aguas de 1953 en favor de la SGAB y su propiedad sobre $500 \mathrm{~km}$ de conducciones del abastecimiento. El asunto está pendiente de casación en el Supremo.

5 Vid. también Informe 1/2012, de la Junta Consultiva de Contratación Administrativa de la Comunidad Autónoma de Aragón, adoptado en su sesión del día 1 de febrero de 2012.
} 
- Acudir a ampliaciones de capital, siempre que la nueva estructura del mismo no modifique las condiciones esenciales de la adjudicación salvo que hubiera estado prevista en el contrato.

- Titulizar los derechos de cobro que ostenten frente a la entidad adjudicadora del contrato cuya ejecución se le encomiende, previa autorización del órgano de contratación, cumpliendo los requisitos previstos en la normativa sobre mercado de valores».

Teniendo en cuenta lo parca e indefinida que puede resultar la referencia «siempre que la nueva estructura del mismo no modifique las condiciones esenciales de la adjudicación» contenida en la primera de las opciones, creemos que a todas luces es recomendable sopesar esa posibilidad de antemano y establecer un régimen expreso y claro sobre este particular en los pliegos de condiciones para evitar litigios futuros. $Y$ lo mismo podría predicarse sobre la posibilidad contemplada en el apartado b).

\section{LA SOCIEDAD DE ECONOMÍA MIXTA EN LA LEGISLACIÓN DE RÉGIMEN LOCAL}

La Ley de Bases de Régimen Local, que, en su actual art. 85.2, marca alguna neta preferencia dentro de las modalidades de la gestión directa, de manera que el recurso de las entidades públicas empresariales y las sociedades mercantiles locales (con integridad de capital social público) requiere la justificación especial que el precepto indica desde la Ley 27/2013, particularmente relacionada con la exigencia de la mayor sostenibilidad y eficiencia que esta Ley introdujo al inicio de ese mismo apartado 2, y no establece de manera explícita prioridad alguna entre las gestión directa y la indirecta de los servicios públicos locales, siempre que, por no implicar ejercicio de potestades públicas -como da a entender el último párrafo del mismo art. 85 por la vía indirecta de remitir a las funciones reservadas a funcionarios por el art. 9 del Estatuto Básico del Empleado Público ${ }^{6}$-, quepa la gestión indirecta.

El Real Decreto Legislativo 781/1986, por el que se aprobó el Texto Refundido de las disposiciones legales vigentes en materia de régimen local, confirmó el viejo principio de que los servicios que impliquen ejercicio de autoridad solo podrán ser ejercidos por gestión directa (art. 95), pero tampoco explicitó nada sobre posible prioridad de la gestión directa o de la indirecta. El Reglamento de Servicios de 1955 reitera asimismo el principio de que serán atendidas necesariamente por gestión directa las funciones que impliquen ejercicio de autoridad (art. 43.1), pero sí dice además algo bien significativo. En su art.45.2, en cuya virtud las municipalizaciones (Alemany Garcías, J., 2018: 125) de servicios económicos, entendidas como la asunción de la gestión directa de éstos (tal y como se desprende del objeto del capítulo tercero de Título III de dicho Reglamento en el que se inserta el precepto, e incluso del tenor del primer apartado del mismo art. 45), tenderán a conseguir que la prestación de los servicios reporte a los usuarios condiciones más ventajosas que las que pudieran ofrecerles la iniciativa particular-obviamente en los servicios no reservados en que ello es posible- y la gestión indirecta.

Es obvio por lo tanto que, mientras la gestión indirecta de un servicio público permite ejercitar, aun limitadamente, la libertad de empresa -y los derechos fundamentales económicos de libertad como la propiedad privada o la libertad de trabajo y profesional- en el ámbito de dicho servicio, precisamente para asumir su gestión por contrato bajo la dirección o supervisión especial de la Administración titular que se fije en él, y -dadas las exigencias generales de la contratación pública- tras competir ofreciendo las mejores condiciones y resultados en el proyecto de esa gestión, la gestión directa en todas sus modalidades comporta el ejercicio de la actividad correspondiente exclusivamente por la Administración titular del servicio a través de sus órganos ordinarios o mediante «el medio propio» o la entidad pública o privada instrumental que para ello se cree o se aproveche, como pura longa manus de la entidad titular, y por lo tanto con total exclusión de la libertad constitucional propia de la iniciativa empresarial privada.

La prioridad de principio de la gestión indirecta no es sino una exigencia intrínseca de coherencia en un sistema constitucional presidido, como acaba de recordarse, por el principio pro libertate, también a los efectos de realizar con la mayor plenitud las exigencias que comportan la cláusula del Estado social, cuya efectividad está vinculada a la más básica del Estado de Derecho. Esto es lo que, en efecto, estaría justificando actualmente al citado art.45.2 del Reglamento de Servicios y lo que subyace asimismo a lo dispuesto

\footnotetext{
6 «En todo caso, el ejercicio de las funciones que impliquen la participación directa o indirecta en el ejercicio de las potestades públicas o en la salvaguardia de los intereses generales del Estado y de las Administraciones Públicas corresponden exclusivamente a los funcionarios públicos, en los términos que en la ley de desarrollo de cada Administración Pública se establezca» (art. 9.2 de la Ley del EBEP, Texto Refundido aprobado por Real Decreto Legislativo 5/2015, de 30 de octubre).
} 
por el segundo párrafo del art. 86.2 de la vigente Ley de Bases de Régimen Local 7/1985, cuando afirma que la efectiva ejecución de estas actividades -las reservadas a las Entidades Locales como el abastecimiento domiciliario y depuración de agitas, o la recogida, tratamiento y aprovechamiento de residuos, incluidos los hídricos- en régimen de monopolio requiere, además del acuerdo de aprobación del pleno de la correspondiente Corporación local, la aprobación del órgano competente de la Comunidad Autónoma. Si la reserva de una actividad de servicio a una entidad pública no es otra cosa que la publificación de ese servicio mediante su conversión en servicio público en sentido estricto, en los términos permitidos por el art. 128.2, segundo inciso, de la Constitución, es evidente que es consustancial a esa reserva la exclusividad o monopolio públicos de la titularidad sobre el servicio reservado.

¿Qué sentido tiene entonces ese párrafo del art. 86.2 de la Ley Local? No puede tener otro que el de exigir ese especial procedimiento, con un control específico autonómico, cuando la modalidad gestora que vaya a aplicarse de manera efectiva comporte lo que ahí se llama un régimen de monopolio, lo que para ser algo distinto de cuanto implica ya la reserva legal el monopolio en la titularidad, ya que habrá de tenerse, en una primera acepción, como la asignación de la gestión en todo el territorio a un solo gestor, sea cual sea éste -excluyendo por tanto la posible concurrencia de gestores en competencia-, pero además, adicional y eventualmente, como la realización más completa de la exclusividad que se producirá con la exclusión de toda apertura periódica de esa gestión única a la competencia «por el mercado» que comporta la contratación para su gestión indirecta por una empresa, de ordinario privada, por un tiempo determinado, al pasar a reservarse también la gestión a la entidad pública titular en cualquiera de las modalidades de la gestión directa ${ }^{7}$.

Por otra parte, hemos de señalar que los primeros antecedentes normativos internos referentes a las empresas mixtas los encontramos justamente en la Ley Municipal Catalana de 1933-1934 (art. 188) y, poco después, en la Ley Municipal Republicana de 1935 (art. 135) (Marqués i Carbó, L. L., 1935). Sin embargo, no se lleva a cabo una regulación detallada de las mismas hasta el Texto Articulado de Régimen Local de 24 de junio de 1955 y el Reglamento de Servicios de las Corporaciones Locales de 17 de junio de 1955 (MartínezAlonso Camps, J. L., 2009: 646 y 647). En la vigente legislación de régimen local, el artículo 85.2 B) de la LBRL prevé, para la prestación por gestión indirecta de los servicios públicos de la competencia local, las distintas formas previstas para el contrato de gestión de servicios públicos en el texto refundido de la Ley de Contratos del Sector Público, aprobado por Real Decreto Legislativo 3/2011, de 14 de noviembre. Referencia hoy huérfana de contenido por remisión a una regulación inexistente por efecto de la derogación del TRLCSP por la nueva LCSP. Por su parte, el artículo 104.1 del TRRL dispone que «para la gestión indirecta de los servicios podrán las entidades locales utilizar las formas de sociedad mercantil o cooperativa cuyo capital social sólo parcialmente pertenezca a la entidad». Y en el apartado segundo, en lo que se refiere a su constitución establece:

«En todo caso, deberá determinarse si la participación de los particulares ha de obtenerse únicamente por suscripción de acciones, participaciones o aportaciones de la empresa que se constituya o previo concurso en que los concursantes formulen propuestas respecto a la cooperación municipal y a la participación en la futura sociedad, fijando el modo de constituir el capital social y la participación que se reserve la entidad local en la dirección de la sociedad y en sus posibles beneficios o pérdidas y demás particulares que figuren en la convocatoria».

En lo relativo al procedimiento de creación, el artículo 104 del RSCL determina que «las empresas mixtas, previo expediente de municipalización o provincialización, podrán quedar constituidas a través de los procedimientos siguientes:

1. ${ }^{\circ}$ Adquisición por la Corporación interesada de participaciones o acciones de Empresas ya constituidas, en proporción suficiente para compartir la gestión social.

2. $\quad$ Fundación de la Sociedad con intervención de la Corporación y aportación de los capitales privados por alguno de los procedimientos siguientes:

7 Aunque obiter dictum, el Consejo de Defensa de la Competencia de Andalucía, en el apdo. 13 de su Informe de 23 de diciembre de 2008 sobre la municipalización del servicio de gestión integral del agua en el Municipio de Nerja (Málaga), mientras afirma que en la gestión directa «la competencia no existe», da a entender que sí hay alguna en fórmulas de gestión indirecta en las «que los ciudadanos del servicio se van a beneficiar de las ventajas de la incorporación a la gestión del servicio público de un [sujeto] privado con un amplio conocimiento en la materia (es lo que se conoce como know how), o de que el servicio se vaya a gestionar desde una entidad especializada en la prestación del servicio del ciclo integral del agua». 
a) Suscripción pública de acciones; o

b) concurso de iniciativas, en el que se admitan las sugerencias previstas en el párrafo 2 del artículo 176 de la Ley.

3. Convenio con Empresa única ya existente, en el que se fijará el Estatuto por el que hubiere de regirse en lo sucesivo».

De toda esta regulación se desprende según Montoya Martín que, aunque esta sea su función más común, la empresa mixta no es sólo un modo de gestión de servicios públicos, sino que puede también constituir una fórmula para el ejercicio actividades económicas privadas para la realización de un interés general.

Prieto González afirma que «esta concepción de la empresa como modo gestor, que ha venido siendo destacada por la práctica totalidad de nuestra doctrina científica, y que le confiere además, en función de los intereses públicos gestionados, sus peculiares características, ha de revisarse sin duda teniendo en cuenta que el papel de las Administraciones locales no se limita ya al de meros gestores de un conjunto de servicios mínimos, sino que persigue sobre todo la finalidad de "satisfacer las necesidades y aspiraciones de la comunidad vecinal", para lo cual podrán incluso "ejercer la iniciativa pública para el ejercicio de actividades económicas" (antiguo art. 86 LBRL). Desde esta perspectiva, la empresa mixta local, configurada legalmente -de acuerdo con la concepción tradicional apuntada- como un modo de gestión de los servicios locales, puede ser, y debe ser también, un instrumento de penetración en aquellos sectores que, sin tener la consideración formal de servicio público, suponen el ejercicio de la iniciativa pública local en la actividad económica» (Prieto González, L. F., 1996: 43 y 44).

José Manuel Sala en su enjundioso artículo en la REDA, en 1996, donde trata de dejar claro que, con la empresa mixta, ciertamente «se trata de obtener que la licitación privada aporte ayuda financiera, experiencia industrial y eficacia gerencial a un servicio público (Merino Estrada, V., 2010: 157-217), sin que la Administración pierda por ello presencia en la dirección y gestión de aquél» participando por tanto «también en la dirección y gestión» de la empresa gestora, siendo, sin embargo, «una exigencia ineludible, derivada de su propia naturaleza y finalidad, que los poderes gerenciales de la sociedad estén en manos del socio privado de la empresa», lo que puede ser posible incluso cuando la participación pública sea mayoritaria ${ }^{8}$ (Sala Arquer, J. M., 1996: 238 y 239), como se sabe hoy bien en cuanto implica el hecho de la influencia dominante. $Y$ dice claramente que solo así puede tratarse propiamente de una gestión indirecta y no de una gestión directa del servicio de que se trate.

Diana Santiago ${ }^{9}$ (Santiago Iglesias, D., 2010: 2.864) ha señalado que «la ausencia de una regulación básica en la materia y las diferentes soluciones adoptadas por los legisladores autonómicos dan lugar a que, en este punto [del porcentaje que ha de alcanzar la participación pública y privada en las sociedades de economía mixta], exista una multitud de modelos de participación pública posible: un modelo de libertad total, donde los Entes públicos pueden participar de forma mayoritaria o minoritaria; un modelo de libertad relativa para los Entes locales, donde éstos han de participar, al menos, en una determinada proporción minoritaria en el capital de la sociedad ${ }^{10}$, y, finalmente, un modelo de participación social pública necesariamente minoritaria». A esta autora simplemente no le «parece necesario exigir que la participación pública tenga carácter mayoritario, puesto que, por una parte, el control sobre la sociedad y, en consecuencia, del interés público que puede estar en juego quedan suficientemente salvaguardados con las potestades que el Ordenamiento jurídico administrativo reconoce a la Administración no solo como titular del servicio, sino, también, como socio público de la sociedad de economía mixta, y, por otra parte, la Administración debe poder escoger, en cada caso, el nivel de participación y de implicación económica que resulte más conveniente para los fines

${ }^{8}$ El autor critica la formulación del art. 155.2 de la Ley 13/1995, de 18 de mayo, de Contratos de las Administraciones Públicas por excluir del régimen del contrato de servicios públicos a las sociedades de Derecho privado con participación mayoritaria de la Administración en su capital, y no sólo cuando su participación sea exclusiva. Pero propone acertadamente interpretar que debería entenderse así sólo cuando esa participación mayoritaria equivalga en sus efectos sobre el poder interno de gestión a la participación exclusiva (ibidem, pág. 244), que no deja de ser una forma de tratar de reconducir la deficiente fórmula al modo como se entiende hoy la influencia dominante pública como determinante de la empresa pública frente a la que no lo es. El texto legal citado de la Ley 13/1995 era mejor, sin embargo, que el que se ha impuesto en la legislación posterior, reduciendo la exclusión a las sociedades cuyo capital sea, en su totalidad, de titularidad pública (art. 8.2 TR de 2011 de la LCSP) y volviendo así a lo que decía el art. 62 de la Ley de Contratos del Estado de 1965.

${ }^{9}$ Como ejemplo del último modelo la autora aporta el art. 215 de la Ley 7/1999, de 9 de abril, de Administración Local de Aragón. Por ella hemos accedido igualmente a la referencia a la Ley Foral que se cita en la nota anterior.

10 Art. 198 de la Ley Foral 6/1990, de 2 de julio, de la Administración Local de Navarra. 
perseguidos con la creación de una sociedad de economía mixta gestora de servicios públicos locales». Aunque no deja de reconocer que las sociedades de economía mixta podrán formar parte del sector público si la Administración local titular del servicio ejerce sobre ellas un control decisivo (por financiarlas, en concreto, mayoritariamente, añadirá), no parece caer en la cuenta de que toda sociedad en la que la influencia dominante sea de la Entidad local titular ha de ser considerada empresa pública ${ }^{11}$, con respecto a la cual las técnicas de control habrán de ser, obviamente, distintas que con respecto a una empresa propiamente privada, aunque participada sin influencia dominante por la Administración. No creemos que en este caso esté legitimado de suyo el ejercicio de particulares potestades internas por parte del socio público, aunque, desde luego, la regulación vigente sea ambigua al respecto.

Sigue señalando Diana Santiago una interesante opinión doctrinal que queremos destacar. Es la siguiente: «dado que uno de los objetivos perseguidos por las Administraciones Públicas con la creación de sociedades de economía mixta es beneficiarse de los conocimientos técnicos y empresariales de gestión que posee el socio privado, los Entes locales deben llevar a cabo una actividad de control sobre el funcionamiento de la sociedad, participando únicamente en las grandes decisiones y dejando en manos del socio privado, mejor conocedor de las técnicas empresariales, la gestión ordinaria de la sociedad de economía mixta», lo que solo puede aceptarse, como es obvio, si la participación de dichos Entes locales carece de influencia dominante ${ }^{12}$. Y de ahí que haya que distinguir también en el caso de la empresa mixta entre las sociedades de mercado, que responderían al principio del accionario patrimonial o financiero, y las sociedades de servicio público. Pues solo estas últimas justifican las derogaciones al Derecho común de sociedades que exija la realización del fin público encomendado (Montoya Martín, E., 2011: 2.969 y 2.970).

En este caso sin perjuicio de la aplicación del Derecho societario propio de la forma mercantil que tenga o tome la sociedad de economía mixta, el Ordenamiento Jurídico-administrativo contiene particularidades que deben tenerse en cuenta en atención a su vinculación a un socio de naturaleza pública y al carácter también público de la relación contractual de da lugar a su creación o a la participación de un socio privado en una sociedad de capital público ya existente. Así, el artículo 104.2 del TRRL permite que en el acuerdo constitutivo se puedan establecer determinadas especialidades que exceptúen la legislación societaria aplicable en la medida necesaria para promover y desarrollar la empresa mixta de carácter mercantil o cooperativo. Esto es, podrán introducirse reglas distintas a las contenidas en las leyes societarias con relación a los órganos de la sociedad, como, por ejemplo, configuración de la Junta General o de otros órganos de gestión o control; así como de carácter funcional, como posibilidad de exigencia de evacuar informes por los funcionarios locales, fiscalización de gastos por parte de la Intervención municipal, exigencia de determinados quórum para la adopción de acuerdos, e incluso posible veto de la Corporación local en relación a determinados acuerdos (González Pueyo, J., 2004).

En el mismo sentido se pronuncian los artículos 287 y 293 de Reglamento de actividades, obras y servicios de las entidades locales de Catalunya $(R O A S)^{13}$. En sus relaciones externas, la actividad contractual de las sociedades mercantiles en cuyo capital sea mayoritaria la participación directa o indirecta de las Administraciones Públicas o de sus Organismos Autónomos, se someterá a los principios de publicidad y concurrencia. Así lo dispone expresamente artículo 182 del Reglamento General de la Ley de Contratos de las Administraciones Públicas (RD 1098/2001, de 12 de octubre de 2001): «En los contratos de gestión de servicios públicos la sociedad de economía mixta figurará como contratante con la Administración, correspondiéndole los derechos y obligaciones propios del concesionario de servicios públicos». En este sentido podemos también acudir a la "Comunicación interpretativa de la Comisión relativa a la aplicación del Derecho comunitario en materia de contratación pública y concesiones a la colaboración público-privada institu-

${ }^{11}$ En su monografía, un poco anterior al artículo que venimos citando, sobre Las Sociedades de economía mixta como forma de gestión de los servicios públicos locales (con prólogo de José Luis Carro Fernández-Valmayor), la misma Diana Santiago asume lo que considera se desprende de la jurisprudencia comunitaria y que inmediatamente consideramos en el texto: que la participación privada en una sociedad impide considerarla «medio propio» de la Administración correspondiente (pág. 75 y ss.)

12 Tal es el caso ya citado de la empresa público-privada Aigües de Barcelona, Empresa Metropolitana de Gestió del Cicle Integral de l'Aigua, participada en un $70 \%$ por Aigües de Barcelona, en un $15 \%$ por el Área Metropolitana de Barcelona (AMB) y en otro $15 \%$ por Criteria, que realiza desde 2013 la gestión del ciclo integral del agua, desde la captación hasta la potabilización, transporte y distribución, encargándose asimismo del servicio de saneamiento y depuración de aguas residuales para su retorno al meen natural o su reutilización. De esta forma, ofrece servicio a cerca de 3 millones de personas en los municipios del área metropolitana de Barcelona. Ya dijimos que el TSJ de Cataluña, en sentencia de 9 de marzo de 2016, ha anulado la adjudicación directa de estos servicios a esta sociedad (con un muy relevante voto particular en contra del presidente de la Sala), lo que está pendiente de un recurso de casación ante el Supremo.

${ }_{13}$ Decreto 179/1995, de 13 de junio. 
cionalizada (CPPI)" ya citada, cuando señala que el objeto del procedimiento en el que se selecciona al socio privado es el contrato público o la concesión que se ha de adjudicar a la entidad de capital mixto, añadiendo que la selección del socio privado va acompañada de la creación de la CPPI y la adjudicación del contrato público o la concesión a la entidad de capital mixto. Pero debe remarcarse también que si bien es cierto que la constitución de una empresa mixta supone la creación de una nueva persona jurídica, no por ello se trasladan a ella las potestades administrativas inherentes a la titularidad del servicio (dirección y control, potestad tarifaría, potestad disciplinaria, etc.), de las que en ningún caso puede desprenderse la Administración ${ }^{14}$.

En referencia al gobierno y a la administración de las sociedades de capital mixta, constituye uno de los principales retos asegurar que en su gobierno y administración se dé el necesario equilibrio entre la responsabilidad pública municipal de ejercer activamente sus funciones de propiedad (como puede ser el nombramiento de los integrantes de órgano de administración) y al mismo tiempo abstenerse de realizar «interferencias políticas» indebidas en la gestión de la empresa ${ }^{15}$. En lo relativo a la organización interna de la sociedad de economía mixta no existe un esquema organizativo determinado con carácter general en la legislación de régimen local, como si sucede en el caso de las sociedades de capital íntegramente público. Con lo cual deberá estarse a las previsiones generales del TRLSC y las breves referencias de legislación local a la Junta General y al Consejo de Administración bajo las premisas que acabamos de exponer.

El Pleno de la Corporación local designará los representantes de la misma en la Junta General de la Sociedad y en lo relativo a la adopción de acuerdos, el RSCL (art. 107) establece que los acuerdos de los órganos de gobierno y administración de la Empresa mixta deberán ser adoptados por la mayoría de tres cuartas partes del número estatutario de votos en los casos de:

a) Modificación del acto de constitución o de los Estatutos de la Empresa.

b) Aprobación y modificación de los planes y proyectos generales de los servicios.

c) Operaciones de crédito.

d) Aprobación de balances.

También el ROAS, en el caso de Cataluña, establece la opción de determinar en los Estatutos sociales o en el acuerdo de constitución la necesidad de un quorum especial, que en todo caso requiera el voto de los representantes locales para la adopción de acuerdos sobre la emisión de obligaciones, aumento o reducción del capital social, transformación, fusión o disolución de la sociedad y en general para cualquier modificación de los estatutos de la sociedad (art. 287).

El Consejo de Administración ha de existir obligatoriamente, como deduce de lo dispuesto en el artículo 108 RSCL, que marca la composición mixta de miembros de la Corporación y técnicos, en la proporción del $50 \%$. Los consejeros nombrados por la Entidad local pueden ser libremente separados por ésta, conforme al artículo 108 del RSCL. El artículo 106 del RSCL establece asimismo que:

a) En la constitución o en los Estatutos de Empresas mixtas podrá establecerse que el número de votos de la Corporación en los órganos de la sociedad, sea la Junta General o el Consejo de Administración, pueda ser inferior a la proporción del capital con que participare en la Empresa, salvo en los cinco años anteriores al término de la misma, en que deberá ser igual o superior.

b) Los acuerdos serán adoptados por mayoría de votos.

c) El cargo de Gerente recaerá siempre en persona especializada designada por el órgano superior de gobierno de la Empresa.

El ROAS, en el caso de Cataluña, refiere también que la representación de la corporación local en los órganos de gobierno y administración de la empresa responde por regla general a su cuota participativa, que las designaciones tanto para la Junta General como para el Consejo de Administración deben recaer en personal profesionalmente calificadas, sean o no miembros de la corporación (art. 288). Y añade que la renovación de las corporaciones locales comporta también la de sus representantes en los órganos de la sociedad, salvo, en su caso la de los administradores, siempre que los Estatutos no prevean otra cosa. Un elemento que a menudo se plantea en relación al Consejo de Administración de las empresas públicas es la posibilidad de la participación de la de la representación de los trabajadores la empresa en su seno. En relación a ello Milans del Bosch y Jordán de Urríes consideran que «Deben crearse procedimientos que faci-

14 Comunicación interpretativa de la Comisión relativa a la aplicación del Derecho comunitario en materia de contratación pública y concesiones a la colaboración público-privada institucionalizada (CPPI) apartado 3.

15 MILANS DEL BOSCH y S. JORDÁN DE URRÍES, op. cit. 
liten la profesionalidad y la verdadera independencia de los miembros del órgano directivo que representan al personal y que garanticen que éstos respetan su deber de confidencialidad. Dichos procedimientos deben incluir mecanismos electorales adecuados, transparentes y democráticos, capacitaciones, y procedimientos claros para la gestión de los conflictos de intereses. Para que los miembros del Consejo de administración que representan al personal puedan contribuir de forma positiva al trabajo del órgano, los demás miembros de éste, así como la administración de la empresa presa pública, deben estar dispuestos a aceptarlos y a cooperar con ellos» ${ }^{16}$. Una reflexión a todas luces pertinente, que bien puede hacerse extensiva todo tipo de representación, considerando que los administradores designados por la corporación local asumen a menudo esta responsabilidad a propuesta de los grupos políticos municipales.

\section{CONSTITUCIÓN DE LAS SOCIEDADES MIXTAS EN EL ÁMBITO LOCAL}

Como ya se ha descrito anteriormente, el artículo 104 del RSCL contempla tres procedimientos por los que puede constituirse una Empresa Mixta. El primero, el de adquisición por la Corporación interesada de participaciones o acciones de empresas ya constituidas, en proporción suficiente para compartir la gestión social. El segundo mediante la fundación de la Sociedad con intervención de la Corporación y aportación de los capitales privados, bien por suscripción pública de acciones, bien por concurso de iniciativas. Y, por último, por convenio con empresa única ya existente, en el que se fijará el Estatuto por el que hubiera de regirse en lo sucesivo. Esta última posibilidad no se contempla no obstante en el TRRL, artículo 104.2, párrafo segundo.

Debe tenerse en cuenta que en este caso nos hallamos simplemente ante un procedimiento de licitación dirigido a la enajenación de una parte de las acciones en que se divide el capital de la Sociedad Municipal sino ante expediente complejo que tiene corno fundamento el cambio en la forma de gestión del servicio público del que se ocupe la sociedad, transformando el modo de gestión directa mediante sociedad mercantil de capital público a la gestión indirecta del mismo a través de sociedad de economía mixta, con el consiguiente establecimiento de unas condiciones jurídicas distintas en que se desarrollará a partir de ese momento la prestación del servicio. Justamente por ello previamente a la transformación de la sociedad se deberá sustanciar la decisión del cambio de forma de gestión del servicio, justificándolo en aras a la sostenibilidad i eficiencia de esa elección (vid. art. 85 de la LBRL) (Renyer Alimbau, J. y Sabaté Vidal, J. M., 2002: 206).

La legislación básica de régimen local no establece un procedimiento específico para determinar la decisión que implica la elección de la forma concreta de gestión de un servicio público local ${ }^{17}$. Para ello según Merino Estrada «si se trata de un servicio que comporta el ejercicio de iniciativa económica, habremos de seguir el detallado procedimiento previsto en el artículo 97 del TRRL. En otro caso, se exigirá únicamente acuerdo del Ayuntamiento Pleno, precedido de una Memoria en la que se acredite que la forma elegida es la que más conviene al interés general. La ausencia de un procedimiento específico no significa que la decisión no tenga que seguir un cauce formal, en el que destacan dos elementos esenciales. En primer lugar, hemos de señalar el órgano competente, que será siempre y en todo caso el Pleno municipal. El acuerdo se adopta por mayoría simple en todos los supuestos. El único caso que requiere mayoría absoluta es el de "municipalización o provincialización en régimen de monopolio", que lógicamente seguirá el procedimiento del artículo 97 del TRRL, reforzado. Cuando el artículo 47.2 k) se refiere a la "aprobación de la forma concreta de gestión del servicio correspondiente", lo hace exclusivamente al servicio "municipalizado" con monopolio. Los supuestos de elección de forma de gestión que no sigan el procedimiento del Art. 97 del TRRL son aprobados siempre por mayoría simple. En segundo lugar, la decisión deberá fundamentarse en una Memoria, con datos objetivos e indicadores de gestión. Lo importante será el criterio seguido y la calidad de los análisis. Pero la forma no debe ser un aspecto a despreciar. Habrá de tratarse de una Memoria bien construida y solvente. La forma de elaboración no tiene por qué ser la establecida en el artículo 97 del TRRL, ni tiene que ser expuesta al público, etc., pero su contenido y estructura sí deberían ser muy similares. Es conveniente que la estructura sea la misma y, en cuanto al contenido, variará en función del servicio de que se trate. Algunos elementos de contenido del Proyecto a que se refiere el artículo 97 del TRRL, como las tarifas o propuestas de precios, de gran importancia en los servicios de contenido económico, pueden no ser necesarios en estos otros supuestos. En todo caso, la Memoria es un elemento esencial del procedimiento» (Merino Estrada, V., 2010: 157-217).

\footnotetext{
16 MILANS DEL BOSCH y S. JORDÁN DE URRÍES, op. cit.

17 Vid. art. 188 y ss. del ROAS.
} 
En lo relativo al procedimiento de licitación cabe decir que además de garantizar los principios de igualdad, concurrencia y no discriminación debe tenerse bien en cuenta que el socio que se vaya a incorporar a la sociedad cuente con la capacidad y la aptitud necesaria para llevar adelante la prestación del servicio. El pliego determinará las condiciones en que se debe de producir la enajenación de los títulos representativos del capital (normalmente mediante ampliación del capital) al socio privado, pero no debe olvidarse que ello no constituye sino un aspecto accesorio o instrumental respecto del objeto principal del contrato, que no es otro que la adjudicación de la gestión del servicio público a la sociedad de economía mixta. Como refiere la Comunicación interpretativa de la Comisión relativa a la aplicación del Derecho comunitario en materia de contratación pública y concesiones a la colaboración público-privada institucionalizada (CPPI) (DOUE de 12 de abril de 2008), «La aportación privada a los trabajos de la CPPI, además de la contribución al capital u otros activos, consiste en la participación activa en la ejecución de las tareas confiadas a la entidad de capital mixto y/o la gestión de dicha entidad». Dicha Comunicación nos recuerda que «El hecho de que una entidad privada y una entidad adjudicadora cooperen en el marco de una entidad de capital mixto no puede justificar que la autoridad contratante no cumpla las disposiciones sobre contratos públicos y concesiones en la adjudicación de contratos públicos o concesiones a esa entidad privada o a la entidad de capital mixto».

Las disposiciones de la legislación comunitaria en materia de contratos públicos y concesiones imponen a la entidad adjudicadora la observancia de un procedimiento equitativo y transparente a la hora de seleccionar al socio privado que, en el marco de su participación en la entidad de capital mixto, realiza suministros, obras o servicios, o cuando adjudica un contrato público o una concesión a la entidad de capital mixto. Ello no supone, sin embargo, que haya de llevarse a cabo una doble licitación, lo que no resultaría práctico. Por tal razón, la Comunicación sugiere, para evitar los problemas derivados de la doble licitación, que el socio privado sea seleccionado «mediante un procedimiento de licitación transparente y competitivo cuyo objeto es el contrato público o la concesión que se ha de adjudicar a la entidad de capital mixto y la contribución operativa del socio privado a la ejecución de esas tareas y/o su contribución administrativa a la gestión de la entidad de capital mixto». La selección del socio privado va acompañada de la creación de la CPPI y la adjudicación del contrato público o la concesión a la entidad de capital mixto. Se refiere, asimismo, a esta materia la Sentencia del Tribunal de Justicia de la Unión Europea de 15 de octubre de 2009, recaída en el Asunto C 196/08. También en ella se indica que recurrir a una doble licitación casa mal con el ahorro de trámites que inspira las colaboraciones público-privadas institucionalizadas, cuya creación reúne en el mismo expediente la selección del socio económico privado y la adjudicación de la concesión a la entidad de capital mixto que debe constituirse únicamente a estos efectos. Y, en línea con lo previamente apuntado, se indica que es posible resolver este problema si se selecciona al socio privado respetando las exigencias de transparencia e igualdad de trato, desde el momento en que se exija a los candidatos que demuestren, no sólo su capacidad para convenirse en accionistas, sino ante todo su capacidad técnica para prestar el servicio y las ventajas económicas y de otro tipo que conlleva su oferta.

\section{LA DISPOSICIÓN ADICIONAL VIGÉSIMO NOVENA DE LA LEY DE CONTRATOS DEL SECTOR PÚBLICO 9/2017 DE 8 DE NOVIEMBRE. ANÁLISIS JURISPRUDENCIAL}

El Informe 2/2012, de 1 de febrero, de la Junta Consultiva de Contratación Administrativa de la Comunidad Autónoma de Aragón («Alcance de la Disposición adicional vigésimo novena del Texto Refundido de la Ley de Contratos del Sector Público, aprobado por Real Decreto Legislativo 3/2011, de 14 de noviembre, en relación con el contrato de gestión de servicios públicos») ${ }^{18}$, interpreta la Disposición adicional vigésimo novena en el sentido de que «la adjudicación directa, a la sociedad de economía mixta, lo es del contrato preciso, concreto y determinado -para el que se ha seleccionado el socio privado-, que debe cumplir con el contenido mínimo del artículo 26 de la LCSP (objeto, precio, duración, condiciones de pago, etc.), más aquellas previsiones relativas a su posible modificación y prórroga. Es decir, la Disposición adicional vigésimo novena de la LCSP no permite adjudicar directamente, a una sociedad de economía mixta, los posibles

18 También es común citar en este contexto la sentencia del TJUE de 15 de octubre de 2009, Asunto C-196/08, Acoset SpA contra Conferenza Sindaci e Presidenza della Prov. Reg. Di Ragusa y otros que han alcanzado celebridad en el mundo jurídico-administrativo. El Informe de la JC de Aragón es seguido, igualmente, por el TARC CyL. Memoria 2012-2014. Adjudicación de contratos a sociedades de economía mixta. 
contratos -a determinar en el futuro-, a modo de una suerte de reserva, de una clase de contratos relacionados con el ciclo del abastecimiento de agua, de forma genérica e indeterminada ${ }^{19}$. Es decir, que «una sociedad de economía mixta, nunca puede ser considerada "medio propio", a los efectos de lo dispuesto en los artículos 4.1, 8.2 y24.6 de la LCSP, tal y como viene fijado por la doctrina del TJUE y, en consecuencia, no pueden encomendársele contratos o concesiones directamente» ${ }^{20}$. En consecuencia, la "Disposición adicional vigésima novena del LCSP, en los contratos de selección de un socio privado, exime de la tramitación de un doble procedimiento de licitación, (selección de socio y selección de adjudicatario) en los supuestos de constitución de una sociedad de economía mixta para la ejecución de una obra o prestación de un servicio, que previamente deben estar definidos y determinados con la precisión que exige la ley en la preparación de todo contrato. La selección del socio privado, deberá cumplir con los requisitos fijados por la doctrina del Tribunal de Justicia que se ha citado en la consideración jurídica IV». Por si no queda claro se concluye también que «no es posible adjudicar directamente ningún contrato ni concesión a una sociedad de economía mixta. Es necesario, siempre, tramitar el procedimiento licitatorio correspondiente para adjudicarle el contrato o concesión de que se trate».

Por otra parte, hemos de señalar que la STSJ de Madrid 822/2015, de 4 de noviembre (RJCA 2015, 980), sobre la base de la STC 103/2015 viene a suponer un respaldo a la legalidad de esta regulación prevista en la Disposición adicional vigésima novena de la LCSP, cuando descarta «el planteamiento de cuestión prejudicial en los términos solicitados por los recurrentes» y explicando las razones que la justifican a la luz de tal sentencia del TC y la Comunicación interpretativa de la Comisión relativa a la aplicación del derecho comunitario en materia de contratación pública y concesiones a la colaboración público-privada institucionalizada (CPPI, 2008/C91/02). Esta STSJ de Madrid 822/2015 se enfrenta con un recurso contencioso-administrativo que tiene por objeto la impugnación, por unos concejales del ayuntamiento, del acuerdo del pleno del ayuntamiento de R., de fecha 17 de febrero de 2012, por el que se aprueba el convenio entre la Comunidad de Madrid, el Canal de Isabel II y el Ayuntamiento de Robledo de Chavela, relativo a la incorporación de dicho Ayuntamiento al futuro modelo de gestión del Canal Isabel II. Como concretos motivos de impugnación se alegan los que, de forma sucinta, a continuación se exponen: 1) No adecuación del convenio impugnado a los artículos 4 y 24.6 del Real Decreto Legislativo 3/2011, de 14 de noviembre, por el que se aprueba el texto refundido de la ley de contratos del sector público al permitir una encomienda de gestión a favor de un ente que no es enteramente público ${ }^{21} ; 2$ ) considera contraria al ordenamiento jurídico el contenido de la estipulación cuarta del convenio en cuanto obliga al ayuntamiento a suscribir un determinado número de acciones sin que se sepa cuál es el valor de las mismas, y a no transmitir un determinado número de acciones; 3) Considera, igualmente, contraria al ordenamiento jurídico la estipulación Quinta del convenio en cuanto

19 Para ello se basa en el siguiente texto de la Comunicación interpretativa de la Comisión: «Según la Comisión, el principio de transparencia impone que se indique claramente en la documentación del anuncio de licitación las posibilidades de renovación o modificación del contrato público o de la concesión adjudicada a la entidad de capital mixto, e indicar las posibilidades de adjudicación opcional de nuevas tareas. La documentación debería indica, al menos, el número y las condiciones de aplicación de esas opciones. La información así ofrecida debe ser lo bastante detallada para garantizar una apertura a la competencia equitativa y eficaz. El TJCE ha observado que las empresas abiertas, incluso parcialmente, al capital privado no se pueden considerar estructuras de gestión "interna" de un servicio público por cuenta de las entidades territoriales a las que pertenecen. De ello se pretende que las normas aplicables a los contratos públicos y las concesiones, tanto si emanan del Tratado CE como de las directivas sobre los contratos públicos, deben cumplirse a la hora de adjudicar a las entidades de capital mixto contratos o concesiones distintos de los licitados en el marco del procedimiento que ha dado lugar a la creación de la CPPI en cuestión. En otros términos, las CPPI deben conservar su campo de actividad inicial y no pueden obtener, en principio, nuevos contratos públicos o concesiones sin un procedimiento de licitación que respete el derecho comunitario en materia de contratos públicos y concesiones...».

20 Caso de una Diputación Provincial (de Teruel) que inició en el año 2000 los trámites para la creación de una empresa mercantil con capital mayoritariamente público (51\%) para la prestación del servicio de aguas en su ciclo integran a los ayuntamientos de la provincia. Para I selección del socio privado de dicha empresa se utilizó la licitación mediante procedimiento abierto y bajo la forma de concurso. El 17 de mayo de 2002 se otorgó la escritura pública de constitución de la sociedad para la gestión del servicio público del ciclo integral del agua en los municipios y otras entidades locales de la provincia de Teruel. Lo que se pretende solventar es «si cabe que la administración otorgue de forma directa la gestión de un servicio público a una sociedad de derecho privado en al que el capital público sea simplemente mayoritario, o si, por el contrario, en tal supuesto el contrato de gestión solo puede adjudicarse con sujeción a las normas establecidas en la Ley de contratos del sector público, es decir, con observancia del procedimiento de adjudicación correspondiente a tenor de lo prevenido en el artículo 159 de dicha ley». en el pliego de prescripciones técnicas se establece concretamente cuales son las tareas encomendada en relación con el ciclo integral del agua.

21 En este sentido alegaban los recurrentes que «la sociedad que va a prestar efectivamente los servicios no es de titularidad totalmente pública. La nueva sociedad va a prestar servicios propios a la Comunidad de Madrid y de los ayuntamientos que se adhieran al nuevo modelo, por lo que cada uno de dichos entes por sí solo no ejerce un control sobre la sociedad de manera análoga a como lo hace sus propios servicios, como exige el ya citado art. 24.6 de la LCSP». 
obliga al ayuntamiento a prorrogar los convenios o incluso extender los que no tuvieran plazo fijado, lo que implica una modificación de los citados convenios sin tramitación de modificación alguna de los mismos; 4) De igual forma considera contraria al ordenamiento jurídico la estipulación Sexta del convenio en cuanto al plazo de duración de 50 años establecido.

A juicio del TSJ, no es legítimo cuestionar el modelo de gestión, al que el convenio impugnado pretende adherirse, pues «ni resulta ser contrario a los ya citados artículos 4 y 26.4 del LCSP, expresamente citados por los recurrentes como infringidos, ni resulta vulnerador del ordenamiento comunitario, en los estrictos términos en los que la contienda ha sido planteada, en la medida, reiteramos, en que la norma cuestionada no impone una encomienda directa sin seguir procedimiento de licitación alguno, contrariamente a lo supuesto por los recurrentes». Y ello ya que, «por tanto, la capitalización o entrada de capital privado procedente de operadores o ciudadanos mediante la enajenación del $49 \%$ del capital como máximo, prevista en el nuevo modelo, en la en que la norma se remite a un momento posterior, estableciendo expresamente que se llevará a cabo en el marco de las previsiones contenidas en la legislación básica del Estado en materia de contratos públicos y mediante un procedimiento que, en todo caso, se ajustará a los principios de igualdad de trato, publicidad y transparencia, es completamente respetuosa con las previsiones al respecto contenidas en la citada LCSP, sin que se advierta, como concluye el Tribunal Constitucional, que la ley imponga una encomienda directa, sin seguir procedimiento alguno de licitación, y al margen de los principios generales que establece el art. 1 de la LCSP, situando a los operadores privados en una situación de ventaja competitiva proscrita por la norma estatal y el derecho europeo. Tanto más cuando el propio legislador señala, en la exposición de motivos de la norma impugnada, que la modificación de este precepto trae causa, precisamente, de la necesidad de adaptar el proceso de capitalización a la disposición adicional vigésimo novena de la LCSP». Es por tanto importante la Comunicación interpretativa de la Comisión relativa a la aplicación del derecho comunitario en materia de contratación pública y concesiones a la colaboración público-privada institucionalizada (Alemany Garcías, J., 2018) (CPPI, 2008/C91/02) cuando considera que los encargos a una sociedad mixta han de hacerse siguiendo la legislación de contratos y que «en cualquier caso, las entidades adjudicadoras no pueden recurrir a mecanismos dirigidos a enmascarar la adjudicación de contratos públicos de servicios a empresas de economía mixta». "El TJCE ha observado que las empresas abiertas, incluso parcialmente, al capital privado no se pueden considerar estructuras de gestión "interna" de un servicio público por cuenta de las entidades territoriales a las que pertenecen». De ello se desprende que las normas aplicables a los contratos públicos y las concesiones, tanto si emanan del Tratado CE como de las directivas sobre los contratos públicos, deben cumplirse a la hora de adjudicar a las entidades de capital mixto contratos públicos o concesiones distintos de los licitados en el marco del procedimiento que ha dado lugar a la creación de la CPPI en cuestión.

Por último, debemos señalar que las CPPI deben conservar su campo de actividad inicial y no pueden obtener, en principio, nuevos contratos públicos o concesiones sin un procedimiento de licitación que respete el derecho comunitario en materia de contratos públicos y concesiones ${ }^{22}$ (Alemany Garcías, J., 2019: 236). Sin embargo, como la CPPI se suele crear para prestar un servicio durante un período bastante largo, debe estar en condiciones de adaptarse a determinados cambios operados en el entorno económico, jurídico o técnico. Las disposiciones comunitarias sobre contratos públicos y concesiones no impiden tener en cuenta estas evoluciones siempre que se cumplan los principios de igualdad de trato y de transparencia. Así, cuando la entidad adjudicadora desea, por motivos concretos, que algunas condiciones de la adjudicación se puedan ajustar tras la elección del adjudicatario, se ha de prever expresamente esa posibilidad de adaptación, así como sus modalidades de aplicación, en el anuncio de licitación o en los pliegos de condiciones, y definir el marco en el que se ha de desarrollar el procedimiento, de manera que todas las empresas interesadas en participar tengan conocimiento de ello desde el inicio y se encuentren, por lo tanto, en pie de igualdad en el momento de presentar su oferta. Cualquier modificación de los términos esenciales del contrato que no se haya previsto en el pliego de condiciones exige un nuevo procedimiento de licitación. El TJCE considera que un término es esencial, en particular, cuando se trata de una estipulación que, de haber figurado en el anuncio de licitación o en el pliego de condiciones, habría permitido a los licitadores presentar una oferta sustancialmente distinta. Cabe citar, como ejemplo de términos esenciales del contrato, el objeto

22 Señala el autor en la pág. 236 que «no creemos que será siempre sencillo acertar en la calificación como contrato o concesión, ya que determinar si el empresario particular va a asumir el riesgo o no, o si el mismo entra en el concepto tradicional de riesgo y ventura del concesionario propios del alea del contrato, es una cuestión que corresponde a la administración o al poder adjudicador que quiera organizar la prestación del servicio». 
REALA. Nueva Época - N.o 12, octubre-marzo 2019 - ISSN: 1989-8975 - DOI: 10.24965/reala.i12.10704 - [Págs. 111-125]

Los encargos a sociedades mixtas en la actual Ley de Contratos del Sector Público

Juan Alemany Garcías

de las obras o los servicios que ha de prestar el adjudicatario, o los cánones impuestos a los usuarios del servicio prestado por el adjudicatario. Esta comunicación desconoce la posible merma o falta de operatividad entonces de este sistema de doble contratación.

\section{CONCLUSIONES}

Primera. En nuestro ordenamiento jurídico, el ya derogado TRLCSP reconocía el contrato de gestión de servicios públicos como una modalidad de gestión indirecta del servicio, en la que la administración encomendaba la gestión de un determinado servicio público a un tercero, normalmente concesionario, figura que desaparece con la entrada en vigor de la LCSP del 2017, surgiendo en su lugar la nueva figura de la concesión de servicios. Sin embargo, en el ámbito local, es escasa la legislación en esta materia, y normas como la LBRL sigue reconociendo el régimen establecido con anterioridad a la nueva LCSP, hoy vacío de todo contenido por ser una revisión de una norma derogada.

Segunda. EI TRRL, en su capítulo II, de actividades y servicios, y concretamente en su artículo 104, establece, para la gestión indirecta de servicios, el empleo de sociedades mercantiles o cooperativas por medio de participación parcial de la entidad local, estableciéndose tres procedimientos para que queden instituidas, el primero de adquisición por la entidad local de participaciones o acciones en empresas ya constituidas, el segundo por medio la fundación de una sociedad con intervención de la entidad local y la aportación de capital privado (ya sea por suscripción pública de acciones o bien por concurso de iniciativa) y el tercer, por medio de convenio con una empresa única ya existente, en el que se fijará el Estatuto por el que hubiera de regirse sucesivo y cabe una cuarta posibilidad, no prevista en el art. 104.2 TRRL, que es la conversión de una sociedad municipal en mixta ya anunciada en el Libro Verde sobre la colaboración público-privada CPP y en la Comunicación interpretativa de la Comisión relativa a la aplicación del Derecho comunitario en materia de contratación pública y concesiones a la colaboración pública-privada institucionalizada.

Tercera. La disposición adicional vigésimo segunda de Ley 9/2017 bajo la rúbrica Adjudicación de contratos de concesión de obras y de concesión de servicios a sociedades de economía mixta. dispone, en su apartado primero, que las concesiones de obras y de servicios podrán adjudicarse directamente a una sociedad de economía mixta en la que concurra mayoritariamente capital público con capital privado, siempre que la elección del socio privado se haya efectuado de conformidad con las normas establecidas en la Ley para la adjudicación del contrato cuya ejecución constituya su objeto, y siempre que no se introduzcan modificaciones en el objeto y las condiciones del contrato que se tuvieron en cuenta en la selección del socio privado. Por todo ello, se reconoce explícitamente que se puede adjudicar directamente un encargo a una sociedad de economía mixta, en forma de concesión de obra y servicio sometiendo la validez de ese encargo a como se ha efectuado la elección del socio privado, y que en la misma elección del mismo no se introduzcan modificaciones a las concesiones de obra y servicio adjudicadas directamente a las sociedades de economía mixta. Hemos de destacar que dicha disposición adicional vigésimo segunda nos parece acertada, ya que siguiendo con la estela del ordenamiento jurídico europeo en el cual a partir del art. 32 y 33 de la ley 9/2017 amplia el ámbito subjetivo de los entes encomendantes-encomendados, incluso a entes que ni siquiera son poder adjudicador, por lo que parece del todo lógico que en determinados supuestos se permita la adjudicación directa de concesiones de contratos concesionales de obras y servicios a la sociedad mixta, aunque el verdadero éxito o fracaso de la disposición se verá en un futuro en la agilidad cotidiana para gestionar las concesiones de las colaboraciones institucionales público-privadas, que también dependerá de la materia sectorial que se gestione por las mismas, y su adecuación a esa peculiar forma de gestión indirecta de un servicio. Para finalizar, queremos destacar la novedad operada por la LCSP en la DA 22, que se refiere a los tipos contractuales para los que se admite la adjudicación directa de contratos a sociedades de economía mixta. Una vez que el objeto del antiguo contrato de gestión de servicios públicos se ha reconducido a los contratos de concesión de servicio y de contrato de servicios, era de esperar que ambos contratos pudieran beneficiarse de la síntesis procedimental de la DA. Es más, desconectada la noción de sociedad de economía mixta del concepto de gestión de servicios públicos ninguna razón habría siquiera para discriminar, en función del objeto del contrato, los supuestos en que poder hacer uso de la adjudicación directa a favor de sociedades de economía mixta. Dicho de otra manera, la desaparición del contrato de gestión de servicios públicos y de sus distintas modalidades como efecto de la Directiva de concesiones parecía sugerir que cobraría plenitud la dicción de la antigua DA $29 .^{a}$ que se refería a que «los contratos públicos [todos ellos] y las concesiones podrán adjudicarse directamente a una sociedad de economía mixta (...) siempre que (...)». 
Podría esperarse, pues, que la ley ampliara las facilidades procedimentales de adjudicación a las sociedades de economía mixta a cualquier contrato público y así aprovechar, cuando conviniera, las ventajas de la colaboración público-privada ínsita en las sociedades de economía mixta, pero no ha sido así.

\section{BIBLIOGRAFÍA}

ALEMANY GARCÍAS, J. (2019): El contrato de concesión de servicios. Un estudio jurídico. Madrid: lustel.

ALEMANY GARCÍAS, J. (2018): La colaboración público-privada institucionalizada en el ámbito urbanístico local. Madrid: Reus.

ALEMANY GARCÍAS, J. (2018): La recuperación de los servicios públicos locales. Madrid: Civitas.

EZQUERRA HUERVA, A. (2018): Contratación pública y Agua. El impacto de la nueva regulación de los contratos públicos en el Derecho de Aguas. Navarra: Thomson Reuters Aranzadi.

GALLEGO CÓRCOLES, I. (2011): "La gestión de servicios públicos mediante de economía mixta en la jurisprudencia europea (I)", en Contratación Administrativa Práctica, núm. 105.

GALLEGO CÓRCOLES, I. y GAMERO CASADO, E. (2018): Tratado de contratos del sector público. Madrid: Tirant lo Blanch.

GIMENO FELIÚ, J. M. (2017): "La nueva Ley de Contratos del Sector Público: un nuevo escenario para la contratación pública", en El Consultor de los Ayuntamientos, núm. 23.

GONZÁLEZ PUEYO, J. (2004): "Gestión de servicios públicos locales. Sociedad mercantil local", ponencia presentada en las Jornadas sobre la Ley de modernización del gobierno local: Una nueva organización para los municipios de "gran población». Recuperado de: http://documentos.famp.es/documentacion/publicaciones/2004grupo9.pdf.

MARQUÉS I CARBÓ, L. L. (1935): La Llei Municipal de Catalunya 1933-1934. Barcelona: Secretariat Català.

MARTÍNEZ-ALONSO CAMPS, J. L. (2009): "Els serveis públics locals (II): prestació indirecta", en GIFREU FONT, J. y FUENTES I GASÓ, J. R.: Régim Jurídic dels Goveni Locals de Catalunya. Valencia: Tirant lo Blanch.

MARTÍNEZ LÓPEZ-MUÑIZ, J. L. (2017): "Sentido y alcance de la transposición de las directivas de la Unión Europea (análisis particular en materia de contratación pública)", en Revista de Administración Pública, núm. 202, págs. 13-41. DOI: $h$ ttp://dx.doi.org/10.18042/cepc/rap.202.01.

MERINO ESTRADA, V. (2010): "Formas de gestión de los servicios locales", en CARBONERO GALLARDO, J. M. (coord.): Teoría y práctica para la gestión de los servicios locales. Madrid: La Ley.

MONTOYA MARTÍN, E. (2011): "La gestión de los servicios locales a través de empresas municipales y mixtas", en MUÑOZ MACHADO, S. (dir.): Tratado de Derecho Municipal. Madrid: Iustel (3. ${ }^{a}$ ed.).

MONTOYA MARTíN, E. (2009): Los medios propios o servicios técnicos en la Ley de contratos del sector público: su incidencia en la gestión de los servicios públicos locales. Barcelona: Fundación Democracia y Gobierno Local.

NOGUERA DE LA MUELA, B. (2012): "Las sociedades de economía mixta como técnica institucional de colaboración pública-privada en el Texto Refundido de la Ley de contratos del Sector Público", en Observatorio de la Contratación Pública. URL: http://www.obcp.es/index.php/mod.opiniones/mem.detalle/id.50/relcategoria.121/ relmenu.3/chk.d38367a4231a7ec12e8af66e915269c1.

PRIETO GONZÁLEZ, L. F. (1996): Las empresas mixtas locales. Madrid: Montecorvo.

REGO BLANCO, M. D. (2017): "Novedades sobre la sociedad de economía mixta en la Ley de Contratos del Sector Público de 2017", en Documentación Administrativa., Nueva Época, núm. 4. DOI: https://doi.org/10.24965/ da.v0i4.10502.

RENYER ALIMBAU, J. y SABATÉ VIDAL, J. M. (2002): "Els serveis públics locals (II)", en GIFREU FONT, J. (coord.): Introducció al Dret Local de Catalunya. Barcelona: Cedecs.

SALA ARQUER, J. M. (1996): "La empresa mixta como modo de gestión de los servicios públicos en la nueva ley de Contratos de las Administraciones Públicas", en Revista Española de Derecho Administrativo (REDA), núm. 90, págs. 233-244.

SANTIAGO IGLESIAS, D. (2010): "La gestión de los servicios públicos locales a través de sociedades de economía mixta", en MUÑOZ MACHADO, S. (dir.): Tratado de Derecho Municipal. Madrid: lustel (3. ${ }^{a}$ ed.).

VIVANCOS MARTÍNEZ, G. J. (2018): "La contratación pública de las sociedades de economía mixta", en Revista de Derecho UNED, núm. 23. DOI: https://doi.org/10.5944/rduned.23.2018.24040. 